\title{
स्वाध्याय का किशोरियों के मानसिक स्वास्थ्य पर प्रभाव का अध्ययन।
}

दीपक सिंह एवं गुंजन शर्मा

सारांश

स्वाध्याय का अर्थ श्रेष्ठ विचारों, श्रेष्ठ चरित्रों, महापुरुषों व सत्साहित्यों के अध्ययन से है, जिनके आधार पर व्यक्ति उनकी वैचारिक भावनात्मक स्थिति के परिप्रेक्ष्य में स्वयं का ऑकलन करता है और उस दिशा में आगे बढ़ने, ऊँचे उठने के लिए आवश्यक प्रेरणा व दिशा प्राप्त करता है। प्रस्तुत शोध का मुख्य उद्देश्य स्वाध्याय का किशोरियों के मानसिक स्वास्थ्य पर पड़ने वाले प्रभाव का अध्ययन करना है। इस अध्ययन में प्रयोगात्मक एवं नियन्त्रित समूह अभिकल्प का प्रयोग किया गया है। अध्ययन हेतु आकर्मिक प्रतिचयन विधि द्वारा श्री राम कॉलेज, मुजफ्फरनगर, उ०प्र० से 16 से 18 वर्ष की 100 छात्राओं का चयन किया गया। जिनमें से 50 छात्राओं को प्रयोगात्मक समूह में तथा 50 छात्राओं को नियन्त्रित समूह में रखा गया। स्वाध्याय हेतु किशोरियों को 3 माह तक सप्ताह में 5 दिन नियमित रुप से 30 मिनट तक स्वाध्याय करवाया गया। मानसिक स्वास्थ्य मापनी द्वारा आकड़ों का संग्रहण 3 चरणो में किया गया। सांख्यिकीय विश्लेषण हेतू एस० पी० एस० एस० वर्जन 18 द्वारा अनोवा परीक्षण का उपयोग किया गया। अध्ययन से प्राप्त परिणामों से यह स्पष्ट होता है कि स्वाध्याय का किशोरियों के मानसिक स्वास्थ्य पर सकारात्मक प्रभाव पड़ता है।

कूट शब्द - मानसिक स्वास्थ्य, स्वाध्याय, किशोरियाँ, अखण्ड ज्योति एवं पंचतन्त्र की कहानियाँ।

मानसिक स्वास्थ्य एक सन्तुलित मानसिक स्थिति को व्यक्त करता है, जो व्यक्ति को सामाजिक रुप से अनुकूल बनाता है और जिसके कारण व्यक्ति अपनी जिन्दगी की सभी समस्याओं से जूझने में सक्षम होता है। मानसिक स्वास्थ्य का अर्थ उत्तम समायोजन की वह अवस्था है, जिसमें कल्याण की आत्मनिष्ठ स्थिति हो; जीने का उत्साह इस स्तर का हो कि व्यक्ति अपनी योग्यताओं एवं कुशलताओं का भरपूर उपयोग कर सके। स्वस्थ मानसिक स्वास्थ्य वाला व्यक्ति धनात्मक स्वप्रत्यय के साथ आत्मसिद्धि की प्राप्ति हेतु प्रेरित होता है। स्वस्थ मानसिक स्वास्थ्य वाले व्यक्ति में संदेह नहीं होता तथा वह अन्तः प्रतिवाद को हटाकर अनियन्त्रित विश्वास से न बँधकर सम्बन्धों में प्रेम, करुणा, देखभाल तथा अपने उत्तरदायित्व को समझता है। ऐसे व्यक्ति में बाह्य वातावरण के प्रति एक उचित दृष्टिकोण होता है तथा वह बाह्य तनाव से मुक्त होने की प्रतिक्रिया को समझता है। Schied \& Brown (2010) के अनुसार-मानसिक स्वास्थ्य में कई आयाम सम्मिलित होते हैं- आत्म सम्मान, अपनी अंतःशक्तियों का अनुभव, सार्थक एवं उत्तम सम्बन्ध बनाए रखने की क्षमता तथा मनोवैज्ञानिक श्रेष्ठता। Deshpanday (2007) ने अपने अध्ययन में बताया कि प्रत्येक व्यक्ति के मानसिक स्वास्थ्य में उसकी भावनाओं की अह्म भूमिका होती है। भावनाएं व्यक्ति के मन की प्रतिरूप होती है। मानसिक स्वास्थ्य व सकारात्मक भावनाओं के बीच सकारात्मक सम्बन्ध होते हैं। सकारात्मक भावनाएं शान्ति, सहृदयता, सन्तुष्टि को बढ़ाने का कार्य करती है, जिससे व्यक्ति का मानसिक स्वास्थ्य बेहतर होने लगता है। जबकि नकारात्मक भावनाएं जैसे- क्रोध, दुश्चिता, घृणा, द्वेष, अवसाद आदि मानसिक स्वास्थ को बिगाड़ने के साथ-साथ रोग
प्रतिरोधी तन्त्र की प्रभावशीलता को कमजोर कर देती है। सकारात्मक भावनाओ में नकारात्मक भावनाओं के प्रभाव को उलट देने की क्षमता होती है (पृ० 67)। सिंह (2003) के अनुसार नैदानिक मनोवैज्ञानिकों ने मानसिक रूप से स्वस्थ व्यक्तियों की कुछ खास विशेषताओं का उल्लेख किया है जिनमें निम्नांकित प्रमुख हैं- आत्म ज्ञान, आत्म मूल्यांकन, आत्म श्रद्धा, सुरक्षा का भाव, संतोषजनक सम्बन्ध बनाए रखने की क्षमता, तनाव एवं अतिसंवेदनशीलता की अनुपस्थिती, अच्छा शारीरिक स्वास्थ्य, जिन्दगी का एक स्पष्ट सिद्धान्त, वास्तविक प्रत्यक्षण तथा स्पष्ट जीवन लक्ष्य। मनोवैज्ञानिक आवश्यकताओं की पूर्ति के लिए भी मानसिक स्वास्थ्य को एक प्रमुख अवयव माना गया है (पृ० 284)।

स्वाध्याय दो शब्दो से मिलकर बना है 'स्व' तथा 'अध्याय'। 'स्व' अर्थात् अपने आपको; 'अध्याय' अर्थात् अध्ययन करना। अतः स्वाध्याय का अर्थ अपने आपको पढना, आत्मचिन्तन करना, जानना-समझना आदि से है (ब्रह्मवचर्स, पृ० 1.49)। प्रस्तुत शोध के अन्तर्गत स्वाध्याय का अर्थ श्रेष्ठ विचारों, श्रेष्ठ चरित्रों, महापुरुषों व सत्साहित्यों के अध्ययन से है, जिनके आधार पर व्यक्ति महापुरुषों की वैचारिक भावनात्मक स्थिति के परिप्रेक्ष्य में स्वयं का ऑकलन करता है और उस दिशा में आगे बढ़ने, ऊँचे उठने के लिए आवश्यक प्रेरणा व दिशा प्राप्त करता है। स्वाध्याय आत्म उन्नति का महान साधन है। वास्तविक स्वाध्याय वही है जिससे व्यक्ति की चिन्ताए दूर हो, शंका-कुशंकाओं का समाधान हो, मन में सद्भाव व शुभ संकल्पों का उदय हो तथा आत्मा को शान्ति का अनुभव हो। सत्साहित्य को माध्यम बनाकर स्वाध्याय करना अधिक सरल है। सत्साहित्य सरलता से उपलब्ध भी हो जाता है, रूचिकर एवं प्रेरणाप्रद भी होता है। इसलिए स्वाध्याय के 
लिए मुख्य रुप से सत्साहित्य को ही चुना जाता है। श्रीराम शर्मा आचार्य के अनुसार जिस प्रकार शरीर को नित्य स्नान कराना आवश्यक है, अन्यथा मैल जम जाएगा, बदबू निकलने लगती है, जिससे अनेक रोग उपज सकते है। ठीक उसी प्रकार से मन को स्नान कराने के लिए स्वाध्याय की आवश्यकता होती है। स्वाध्याय में प्रमाद करने से मन के ऊपर विकारों की परत जम जाती है, जिससे मनोविकार उपजते है, मानसिक रोगों का उद्भव होता है। मन की मलिनता से शरीर भी रोगी हो जाता है। स्वाध्याय की उपेक्षा करना, उसमें प्रमाद बरतना मन को रोगी बनाने के समान है (ब्रह्मवचर्स, पृ० 2.58)।

मनुष्य विचारों का पुन्ज है। अपने दृष्टिकोण के आधार पर वह अपने जीवन के बाह्य और आन्तरिक स्तर को निर्मित करता है। स्कूलों, कॉलेजों, में पढ़ाई जाने वाली शिक्षा, जीविकोपार्जन एवं लोक व्यवहार में निपुणता प्राप्त करने के लिए होती है। यह आवश्यक भी है; क्योकि इसके बिना सांसारिक जीवन में सुस्थिरता एवं उन्नति का मार्ग नहीं खुलता। लेकिन इससे भी आवश्यक विद्या है, जिस ज्ञान को प्राप्त कर मनुष्य उच्च मान्यताओं, आकांक्षाओं एवं आदर्शों का निर्माण करता है, इसे प्राप्त करने का माध्यम स्कूल, कॉलेज नहीं वरन् स्वाध्याय एवं सत्संग है। चिन्तन और मनन से, सत्साहित्य पढ़ने से, सज्जनों के साथ रहने, उनके अभिवचन सुनने और कार्य कलाप देखने से विद्या का आविर्भाव होता है (ब्रहमवर्चस, 1991, पृ0 15.16)।

Lee et al., (2014) के द्वारा किए गए अध्ययन में 268 बच्चों को (जिनकी उम्र 3 से 7 वर्ष की थी), खेल के समय तीन समूहों में विभाजित किया और तीनां समूहों को अलग-अलग नैतिक मूल्यों से सम्बन्धित कहानियाँ सुनाई गई। परिणाम में यह पाया गया कि- जिन बच्चों को ईमानदारी से सम्बन्धित नैतिक कहानियाँ सुनाई गई उन्होंने अन्य दोनों समूहों के बच्चों की तुलना में अधिक ईमानदारी का प्रदर्शन किया। इसके आधार पर अध्ययनकर्ताओं ने यह निष्कर्ष दिया कि पारम्परिक नैतिक कहानियाँ बच्चों में स्वाभाविक रूप से नैतिक व्यवहार को प्रेरित करती हैं। इसी प्रकार Billingtion (2015) ने यूनाइटेड किंगडम में 4164 युवाओं पर अध्ययन किया, जो नियमित रुप से पठन क्रिया में संलग्न रहते थे। इस शोध का मुख्य उद्देश्य पढ़ने का व्यक्ति के सामान्य मनोदशा, स्वस्ति भावना, सामाजिक अन्तःक्रिया से सम्बन्ध का अध्ययन करना था। परिणाम मे इन्होंने पाया कि- जो लोग स्वेच्छा से सुख प्राप्ति के लिए अध्ययन करते हैं, उनमें अपने समूह के प्रति अधिक जागरुकता, अधिक सामाजिक समावेशितता, सामाजिक अवसरों में अधिक प्रसन्नतापूर्वक भागीदारी तथा खुलेपन की भावना में वृद्धि पाई गई। अतः स्पष्ट है कि स्वाध्याय एक महत्वपूर्ण प्रक्रिया है जो व्यक्ति के जीवन पर सकारात्मक प्रभाव डालता है। प्रस्तुत शोध
का उद्देयश्य स्वाध्याय का किशोरियों के मानसिक स्वास्थ्य पर प्रभाव का अध्ययन करना है।

\section{प्रतिदर्श एवं प्रतिदर्श चयन विधि}

प्रस्तुत अध्ययन हेतु 'आकस्मिक प्रतिचयन विधि' द्वारा श्री राम कॉलेज, मुजफ्फरनगर, उ०प्र० से 100 छात्राओं का चयन किया गया। जिनमें से 50 छात्राओं को प्रयोगात्मक समूह में तथा 50 छात्राओं को नियन्त्रित समूह में सम्मिलित किया गया है।

\section{समावेशन एवं अपवर्जन मापदण्ड}

प्रस्तुत शोध में 16 वर्ष से 18 वर्ष तक की उन्हीं किशोरियों को सम्मिलित किया गया जिनकी शैक्षणिक योग्यता कम से कम हाईस्कूल थी तथा जो शारीरिक मानसिक रूप से स्वस्थ थी। शोध में उन किशोरियों को सम्मिलित नहीं किया गया जो किसी प्रकार से शारीरिक व मानसिक रूप से अस्वस्थ थी।

\section{अनुसंधान अभिकल्प}

प्रस्तुत अध्ययन में 'प्रयोगात्मक एवं नियन्त्रित समूह अभिकल्प' का उपयोग किया गया। जिसमें शोधकर्ता प्रतिदर्श को दो समूहों में विभाजित कर लेता है। जिनमें एक समूह को प्रयोगात्मक परिस्थिति में तथा दूसरे समूह को नियन्त्रित परिस्थिति में रख कर अध्ययन किया जाता है। अध्ययन से पूर्व व पश्चात् दोनों समूहों में आश्रित चर का मापन कर तुलना की जाती है।

\section{प्रयुक्त परीक्षण}

मानसिक स्वास्थ्य को मापने के लिए अरूण कुमार सिंह और अल्पना सेन गुप्ता (2000) द्वारा निर्मित मानसिक स्वास्थ्य मापनी का उपयोग किया गया है। इस परीक्षण में कुल 130 पद हैं जो मानसिक स्वास्थ के दिए गए सांवेगिक स्थिरता, पूर्ण समायोजन, स्वायत्ता, सुरक्षा-असुरक्षा, आत्म-सम्प्रत्यय तथा बुद्धि के आयामों से सम्बन्धित हैं।

\section{कार्य विधि}

प्रस्तुत अध्ययन हेतु आकस्मिक प्रतिचयन विधि द्वारा श्री राम कॉलेज, मुजफ्फरनगर, उ०प्र० से 16 से 18 वर्ष की 100 छात्राओं का चयन किया गया, जिनमें से 50 छात्राओं को प्रयोगात्मक समूह में तथा 50 छात्राओं को नियन्त्रित समूह में सम्मिलित किया गया है। शोध में सम्मिलित प्रयोगात्मक समूह की किशोरियों को स्वाध्याय का अभ्यास करवाया गया। स्वाध्याय हेतु प्रयोज्यों को अखण्ड ज्योति मासिक पत्रिका तथा पंचतन्त्र की कहानियों का अध्ययन तीन माह तक 30 मिनट (सप्ताह में 5 दिन) करवाया गया। जबकि नियन्त्रित समूह की छात्राओं को किसी प्रकार का 
अभ्यास नहीं करवाया गया। मानसिक स्वास्थ्य मापनी द्वारा दोनों समूह की किशोरियों के मानसिक स्वास्थ्य का तीन चरणों (1) अध्ययन से पूर्व अवस्था, (2) 45 दिनों बाद मध्य अवस्था में तथा (3) तीन माह बाद अन्तिम अवस्था में मापन कर आंकडों का संग्रह किया गया।

\section{सांख्यिकीय विश्लेषण}

प्रस्तुत शोध से प्राप्त आकड़ों के सांख्यिकीय विश्लेषण हेतु एस पी एस एस वर्जन 18 के माध्यम से 'वन वे अनोवा' परिक्षण का उपयोग किया गया है।

\section{शोध परिणाम}

सांख्यिकीय विश्लेषण से प्राप्त शोध परिणाम इस प्रकार है-

\section{प्रयोगात्मक समूह}

Table (1): Descriptive

\begin{tabular}{|c|l|l|l|}
\hline Tests & N & Mean & SD \\
\hline Pre-test & 50 & 72.62 & 7.98 \\
\hline Mid-test & 50 & 88.58 & 8.94 \\
\hline Post-test & 50 & 105.98 & 8.97 \\
\hline
\end{tabular}

Table (2): ANOVA

\begin{tabular}{|l|c|c|c|c|c|}
\hline Groups & $\begin{array}{c}\text { Sum of } \\
\text { Squares }\end{array}$ & df & $\begin{array}{c}\text { Mean } \\
\text { Square }\end{array}$ & F & Sig. \\
\hline Between & 27839.52 & 2 & 13919.76 & 186.21 & .000 \\
Within & 10988.94 & 147 & 74.755 & & \\
Total & 38828.46 & 149 & & & \\
\hline
\end{tabular}

Table (3): Multiple Comparisons (Tukey HSD)

\begin{tabular}{|l|l|l|l|}
\hline (i)conditions & (j)conditions & $\begin{array}{l}\text { Mean } \\
\text { Difference (i-j) }\end{array}$ & Sig. \\
\hline Pre-test & Mid-test & -15.96 & .00 \\
\hline Pre-test & Post-test & -33.36 & .00 \\
\hline Mid-test & Post-test & -17.40 & .00 \\
\hline
\end{tabular}

प्रयोगात्मक समूह से प्राप्त आकड़ों का वन वे अनोवा द्वारा सांख्यिकीय विश्लेषण के आधार पर प्राप्त परिणाम से यह स्पष्ट होता है कि विभिन्न समुहों के बीच सांख्यिकीय रूप से सार्थक अंतर है $(F=186.206, P=.000)$ । Tukey Post Hoc Test से यह स्पष्ट होता है कि पूर्व परीक्षण $(72.62 \pm 7.98)$ की तुलना में मध्य परीक्षण $(88.58 \pm 8.94, \mathrm{P}=.000)$ व पश्चात परीक्षण $(105.98 \pm 8.97, P=.000)$ तथा मध्य परीक्षण की
तुलना में पश्चात परीक्षण $(P=.000)$ के बीच सांख्यिकीय रूप से सार्थक अन्तर है। अथार्त पूर्व परीक्षण की तुलना में मध्य परीक्षण व पश्चात परीक्षण के मान में तथा मध्य परीक्षण की तुलना में पश्चात परीक्षण के मान में सांख्यिकीय रूप से सार्थक वृद्धि हुई है।

\section{अप्रयोगात्मक समूह}

Table (4): Descriptive

\begin{tabular}{|c|c|c|c|}
\hline Tests & N & Mean & SD \\
\hline Pre-test & 50 & $87-22$ & $12-81$ \\
\hline Mid-test & 50 & $89-14$ & $12-69$ \\
\hline Post-test & 50 & $89-34$ & $13-30$ \\
\hline
\end{tabular}

Table (5): ANOVA

\begin{tabular}{|l|c|c|c|c|c|}
\hline Groups & $\begin{array}{c}\text { Sum of } \\
\text { Squares }\end{array}$ & df & $\begin{array}{c}\text { Mean } \\
\text { Square }\end{array}$ & F & Sig. \\
\hline Between & 137.013 & 2 & 68.507 & .409 & .665 \\
\hline Within & 24617.820 & 147 & 167.468 & & \\
\hline Total & 24754.833 & 149 & & & \\
\hline
\end{tabular}

Table (6): Multiple Comparisons (Tukey HSD)

\begin{tabular}{|l|l|l|l|}
\hline (i)conditions & (j)conditions & $\begin{array}{l}\text { Mean } \\
\text { Differences (i-j) }\end{array}$ & Sig. \\
\hline Pre-test & Mid-test & -1.92 & .739 \\
\hline Pre-test & Post-test & -2.12 & .692 \\
\hline Mid-test & Post-test & -.20 & .997 \\
\hline
\end{tabular}

अप्रयोगात्मक समूह से प्राप्त आकड़ों का वन वे अनोवा द्वारा सांख्यिकीय विश्लेषण के आधार पर प्राप्त परीणाम से यह स्पष्ट होता है कि विभिन्न समुहों के बीच सांख्यिकीय रूप से सार्थक अंतर नहीं है $(F=0.409, P=.665)$ । Tukey Post Hoc Test से भी यह स्पष्टी होता है कि पूर्व परीक्षण $(87.22 \pm$ 12.81) की तुलना में मध्य परीक्षण (89.14 \pm 12.69 , $\mathrm{P}=.739)$ व पश्चात परीक्षण $(89.34 \pm 13.30, \mathrm{P}=.692)$ तथा मध्य परीक्षण की तुलना में पश्चात परीक्षण $(P=.997)$ के बीच सांख्यिकीय रूप से सार्थक अन्तर नहीं है। अथार्त पूर्व परीक्षण की तुलना में मध्य परिक्षण व पश्चात परीक्षण के मान में तथा मध्य परीक्षण की तुलना में पश्चात परीक्षण के मान में सांख्यिकीय रूप से सार्थक वृद्धि नहीं हुई है।

उपरोक्त विश्लेषण से यह स्पष्ट होता है कि स्वाध्याय करने वाली किशेरियों के समूह के मानसिक स्वास्थ्य के पूर्व, मध्य तथा अन्तिम अवस्था के मध्यमानों के बीच सांख्यिकीय रूप से 
सार्थक अन्तर प्राप्त हुए जबकि अप्रयोगात्मक समूह की किशोरियों के मानसिक स्वास्थ्य के पूर्व, मध्य तथा अन्तिम अवस्था के मध्यमानों के बीच में कोई सार्थक अन्तर प्राप्त नहीं हुए। इसका अभिप्राय यह है कि स्वाध्याय का किशेरियों के मानसिक स्वास्थ्य पर सकारात्मक प्रभाव पड़ता है। अतः परिणामों के अनुरूप शून्य परिकल्पना अस्वीकृत की जाती है।

\section{परिणामों की व्याख्या}

प्रस्तुत शोध से यह निष्कर्ष प्राप्त होते हैं कि स्वाध्याय का किशोरियों के मानसिक स्वास्थ्य पर सकारात्मक प्रभाव पड़ता है। तथा स्वाध्याय करने वाली तथा स्वाध्याय न करने वाली किशोरियों के मानसिक स्वास्थ्य में सार्थक अन्तर प्राप्त हुआ। स्वाध्याय एक सरल, मनोरंजक व ज्ञानवर्धक प्रक्रिया है। जिसके माध्यम से व्यक्ति को अपने आपको जानने समझने व विकसित करने का अवसर प्राप्त होता है। वास्तव में सद्साहित्य संत, तपस्वी, ज्ञानी व महापुरूषों के जीवन के अनुभव का सार होता है। जो व्यक्ति के जीवन की समस्याओं का समाधान करने के साथ जीवन को सही दिशा प्रदान करता है। मनोवैज्ञानिक दृष्टि से देखे तो यह एक मनोविश्लेषण व संज्ञानात्मक पुनःसंरचना की प्रक्रिया है। स्वाध्याय द्वारा आत्मविश्लेषण कर जीवन से जुड़े द्वन्द्वों, भ्रमों, कुण्ठाओं आदि समस्याओं को समझने व उन्हें दूर करने का अवसर व मार्गदर्शन प्राप्त होता है, जिसके परिणामस्वरूप व्यक्ति के मानसिक स्वास्थ्य में वृद्धि होती है।

मानसिक स्वास्थय ही सफलता की कुन्जी है और मानसिक स्वास्थ्य का आधार मानसिक प्रक्रियाएँ हैं। इन मानसिक प्रक्रियाओं में व्यक्ति के चिन्तन, सोचने समझने का ढंग, अभिवृत्तिया आदि सभी सम्मिलित होती है और इन मानसिक प्रक्रियाओं का आधार होते हैं- सूक्ष्म विचार। ये विचार अत्यन्त संक्रामक, संवेदनशील तथा प्रभावग्राही होते है और इन विचारों के नियन्त्रण का श्रेष्ठ माध्यम है- स्वाध्याय। स्वाध्याय का तात्पर्य श्रेष्ठ विचारों, श्रेष्ठ चरित्रों, महापुरूषों व सत्साहित्यों के अध्ययन से है। जिनके आधार पर व्यक्ति महापुरूषों की वैचारिक, भावनात्मक स्थिति के परिप्रेक्ष्य में स्वयं का ऑकलन करता है और उस दिशा में आगे बढ़ने, ऊँचे उठने के लिए आवश्यक प्रेरणा व दिशा प्राप्त करता है। श्रीराम शर्मा आचार्य के अनुसार सद्रन्थों के अध्ययन व मनन के माध्यम से मानसिक परिष्कार की एक ऐसी मनोवैज्ञानिक प्रक्रिया आरम्भ होती है, जिसके परिणाम स्वरूप अध्ययनकर्ता का दृष्टिकोण स्वस्थ विधेयात्मक होने के साथ-साथ, उसके व्यक्तित्व विकास को प्रेरणा देने के लिए और जीवन को दिशा और दशा भी प्राप्त होती है। स्वाध्याय द्वारा व्यक्ति आत्मनिर्माण करता हुआ आत्मविकास के पथ पर अग्रसर होता है। इसलिए स्वाध्याय को सत्पथ प्रदर्शक भी कहा गया है; क्योंकि इसके बिना जीवन को भटकाव से बचाना मुश्किल है (ब्रह्मवर्चस,
पृ० 2.6)। अतः स्वाध्याय के लिए प्रयुक्त किए गए माध्यम अखण्ड ज्योति मासिक पत्रिका तथा पन्चतन्त्र की कहानियाँ किशोरियों को उनके मानसिक स्वास्थ्य के प्रबन्धन तथा विकास के लिए प्रभावी साबित हुई। प्रस्तुत परिणाम Twist et al., (2007) के सर्वेक्षण अध्ययन से प्राप्त निष्कर्षों के समकक्ष है। अपने अध्ययन से प्राप्त निष्कर्षों के आधार पर इन्होंने यह तथ्य दिए कि आधुनिक माध्यम जैसे इन्टरनेट से अध्ययन की अपेक्षा पारम्परिक माध्यम जैसे पुस्तकों का अध्ययन अधिक लाभप्रद होता है। जिनसे पाठक के मानसिक स्वास्थ्य का विकास होता है। श्रीराम शर्मा आचार्य के अनुसार अच्छी पुस्तकों में अच्छे विचार होते हैं। अच्छे विचार, अच्छी भावनाएँ, अच्छी कल्पनाए जहाँ भी हैं वहॉ स्वर्ग का सा वातावरण होता है। अच्छी पुस्तकों के अभाव में मनुष्य उस ज्ञान राशि से वंचित रह जाता है जिससे मानसिक अस्तित्व निष्प्राण रह जाता है। स्कूली शिक्षा ज्ञान की श्रेणी में नहीं आती बल्कि वह ज्ञान प्राप्ति का साधन मात्र है; क्योंकि भाषा ज्ञान के बिना शास्त्रों व साहित्य का अध्ययन नहीं हो सकता। शासत्रों व सद्साहित्य का अध्ययन व्यक्तित्व के निर्माण में महत्वपूर्ण भूमिका निभाता है; क्योंकि व्यक्तित्व विकास मानसिक स्वास्थ्य पर निर्भर करता है और मानसिक स्वास्थ्य व्यक्ति के विचारों तथा उसके बौद्धिक स्तर पर ही निर्भर करता है, जिसके पोषण का प्रभावी माध्यम स्वाध्याय ही है (ब्रहमवर्चस, 1991, पृ0 15.16)।

कश्यप (2009) द्वारा स्वाध्याय का मानसिक स्वास्थ्य पर प्रभाव का अध्ययन किया गया। जिसमें 90 विद्यार्थियों को प्रायोगिक व नियन्त्रित समूह में बांटा गया। प्रयोगात्मक समूह के विद्यार्थियों को नियमित रूप से स्वाध्याय करवाया गया। जिससे यह निष्कर्ष प्राप्त हुए, कि स्वाध्याय के नियमित अभ्यास से प्रयोगात्मक समूह के विद्यार्थियों का मानसिक स्वास्थ्य स्तर उन्नत पाया गया। Howrd (2011) द्वारा 12 से 15 वर्ष के 68 हाईस्कूल के बच्चों पर पठन का उनके सन्तुष्टि तथा अभिप्रेरणा स्तर पर प्रभाव का अध्ययन किया गया। जिसमें यह पाया गया कि पढ़ने के कारण इन छात्रों की अध्ययन की योग्यता का विकास, विचार क्षमता का विकास, दुनिया को और बेहतर ढंग से समझने की क्षमता का विकास, सामाजिक जागरुकता तथा सहानुभूति का विकास, मनोरंजन तथा दैनिक जीवन की समस्याओं से छुटकारा, मजबूत विश्वासों की दृढ़ता तथा उन्हें क्रियान्वयन में लाने की क्षमता का विकास होता है। Clark and Rumbold (2006) ने अपने अध्ययन के आधार पर यह तथ्य प्रस्तुत किए कि जब लोग स्वतः अपनी खुशी के लिए अध्ययन करते हैं तो इससे उनके शैक्षिक उ़द्वेश्य की पूर्ति के साथ उनका व्यक्तित्व विकास भी होता है। व्यक्तित्व का विकास व्यक्ति के शारीरिक, मानसिक, संवेगात्मक, सामाजिक, आध्यात्मिक पहलुओं के संयुक्त विकास का परिणाम होता है। स्वाध्याय के माध्यम से अर्जित ज्ञान द्वारा व्यक्ति अपने स्वास्थ्य के संरक्षण के साथ-साथ 
मानसिक स्वास्थ्य हेतु पर्याप्त ज्ञान भी अर्जित कर लेता है। वह अपनी समस्याओं के समाधान हेतु अनुभवी व श्रेष्ठ व्यक्तियों के विचारों से मार्गदर्शन प्राप्त कर लेता है। जो विचारशील व्यक्ति होते हैं अथवा जीवन और समाज के प्रति थोड़ा सा भी सुलझा हुआ दृष्टिकोण रखते हैं वे शिक्षा तथा ज्ञान के महत्त्व को स्वीकार करते हैं। अतः स्वाध्याय व्यक्ति के मानसिक स्वाथ्सय, मानसिक विकास तथा जीवन की सफलता के लिए सुलभ तथा अनिवार्य प्रक्रिया है।

\section{निष्कर्ष}

शोध परिणामों से यह स्पष्ट होता है कि स्वाध्याय का किशोरियों के मानसिक स्वास्थ्य पर सकारात्मक प्रभाव पड़ता है। अतः स्वाध्याय मानसिक स्वास्थ को उन्नत बनाने की एक प्रभावशाली प्रक्रिया है। इस प्रकार यह कहा जा सकता है कि यदि स्वाध्याय का नियमित रूप से अभ्यास किया जाए तो किशोरियों के लिए मानसिक स्वास्थ्य के संरक्षण, संवर्धन के साथ-साथ स्वाध्याय से प्राप्त होने वाले अन्य लाभों को भी प्राप्त किया जा सकता है।

दीपक सिंह, पी-एच०डी०., सहायक प्राध्यापक; गुंजन शर्मा शोधार्थी, मनोविज्ञान विभाग, देव संस्कृति विश्वविद्यालय, हरिद्वार।

\section{सन्दर्भ सूची}

कश्यप, सुभाष (2009). प्रज्ञायोग व्यायाम, नादयोग व स्वाध्याय का विद्यार्थियों के मानसिक स्वास्थ्य व आशावादी निराशावादी मनोवृत्ति पर प्रभाव (शोध प्रबन्ध)। देव संस्कृति विश्वविद्यालय- हरिद्वार।

पण्ड्या, प्रणव (नवम्बर, 2014). सदा सकारात्मक रखे सोच। अखण्ड ज्योति, 11,40 मथुरा- अखण्ड ज्योति संस्थान।

ब्रह्मवर्चस (nd). आत्मोत्कर्ष का आधार ज्ञान (पं. श्रीराम शर्मा आचार्य वाड्मय)। मथुरा- अखण्ड ज्योति संसथान।
ब्रहमवर्चस (1991). शिक्षा और विद्या का सार्थक समन्वित स्वरुप। हरिद्वारशान्तिकुन्ज।

$\begin{array}{ll}\text { सिंह, अरुण कुमार } & \text { (2005). मानसिक स्वास्थ्य नैदानिक मनोविज्ञान (तृतीय संशोधित }\end{array}$ संस्करण)। दिल्ली- मोतीलाल बनारसीदास पब्लिकेशन हाउस।

Billington, J. (2015). Reading between the Lines: the Benefits of Reading for Pleasure. University of Liverpool. Retrived from http://manuscritdepot.com/documentspdf/Galaxy-Quick-Reads-

Report-FINAL\%20.pdf on 10/01/2017

Clark, C. \& Rumbold, K. (2006). Reading for Pleasure a Research Overview. The National Literacy Trust, 9, 1-25. Retrived from http://www.literacytrust.org.uk/assets/0000/0562/Reading_pleasure_2 006.pdf

Deshpande, C. G. (2007). Role of Emotion in Individual Mental Health. New Delhi :Yoga Mararji Desai National Institute of Yoga.

Howard, V. (2011). The importance of pleasure reading in the lives of young teens: Self-identification, Self-construction and Selfawareness. Journal of Librarianship and Information Science, 43(1), $46-55$

Lee, K., Talwar, V., McCarthy, A., Ross, I., Evans, A. \& Arruda, C. (2014). Can Classic Moral Stories Promote Honesty in Children? Psychological Science. Retrived from http://journals.sagepub.com /doi/abs/10.1177/0956797614536401

Sheid, T. L. \& Brown, T. N. (2010). A handbook for the study of Mental Health. Social Contexts, Theories, and Systems (Second Edition, p.1). New York: Combridge University Press.

Twist, L., Schagen, I. \& Hodgson, C. (2007). Readers and Reading. National Report for England 2006. Slough: NFER 